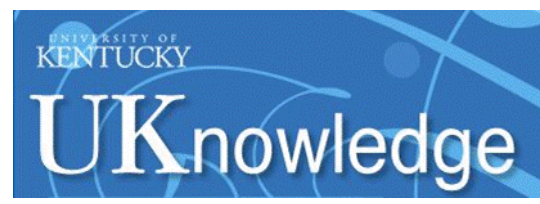

University of Kentucky

UKnowledge

8-2018

\title{
An Electromyography Study of Muscular Endurance during the Posterior Shoulder Endurance Test
}

\author{
Neil A. Evans \\ University of Kentucky, evansn@marshall.edu \\ Emily Dressler \\ Wake Forest University \\ Timothy L. Uhl \\ University of Kentucky, tluhl2@uky.edu
}

Follow this and additional works at: https://uknowledge.uky.edu/rehabsci_facpub

Part of the Biomechanics Commons, Exercise Science Commons, and the Rehabilitation and Therapy Commons

Right click to open a feedback form in a new tab to let us know how this document benefits you.

\section{Repository Citation}

Evans, Neil A.; Dressler, Emily; and Uhl, Timothy L., "An Electromyography Study of Muscular Endurance during the Posterior Shoulder Endurance Test" (2018). Physical Therapy Faculty Publications. 91. https://uknowledge.uky.edu/rehabsci_facpub/91

This Article is brought to you for free and open access by the Physical Therapy at UKnowledge. It has been accepted for inclusion in Physical Therapy Faculty Publications by an authorized administrator of UKnowledge. For more information, please contact UKnowledge@lsv.uky.edu. 


\section{An Electromyography Study of Muscular Endurance during the Posterior Shoulder Endurance Test}

Digital Object Identifier (DOI)

https://doi.org/10.1016/j.jelekin.2018.05.012

Notes/Citation Information

Published in Journal of Electromyography and Kinesiology, v. 41, p. 132-138.

(c) 2018 Elsevier Ltd.

This manuscript version is made available under the CC-BY-NC-ND 4.0 license

http://creativecommons.org/licenses/by-nc-nd/4.0/.

The document available for download is the authors' post-peer-review final draft of the article. 
1 An Electromyography Study of Muscular Endurance during the Posterior Shoulder

2 Endurance Test

3

$4 \quad$ Neil A. Evans, PT, DPT 1,2

5 Emily Dressler, Ph.D. ${ }^{3}$

6 Tim Uhl, Ph.D., PT, ATC ${ }^{2}$

7 1School of Physical Therapy, Marshall University, Huntington, WV, USA

$8 \quad{ }^{2}$ Department of Rehabilitation Science, University of Kentucky, Lexington, KY, USA

$9{ }^{3}$ Department of Biostatistical Science, Wake Forest University, Winston-Salem, NC, 10 USA

11 Address correspondence to Neil A. Evans, 2847 Fifth Avenue, Huntington, WV 25702,

12 Email: evansn@marshall.edu

13

14 Key Words: Fatigue; Shoulder horizontal abduction; Median frequency

15 The authors certify that they have no financial interest in the subject matter or materials 16 discussed in the article. 
The primary purpose was to determine if there is a difference between the median frequency slopes of 5 posterior shoulder muscles during the initial portion of the Posterior Shoulder Endurance Test (PSET) at the $90^{\circ}$ and $135^{\circ}$ shoulder abduction

4 positions.

Fifty-five healthy volunteers (31 females) participated. The median frequency of the posterior deltoid (PD), upper trapezius (UT), middle trapezius (MT), lower trapezius

7 (LT), and infraspinatus (INF) was measured during the PSET at $90^{\circ}$ and $135^{\circ}$ of

8 shoulder abduction. External torque of $13 \pm 1 \mathrm{Nm}$ was used for females and $21 \pm 1 \mathrm{Nm}$ for

9 males. A fixed effect multi-variable regression model was used to investigate the 10 median frequency slopes. Males and females were analyzed separately. Median frequency slopes demonstrated fatigue in all 5 of the muscles. The PD

12 fatigued greater than the UT in males $(p=0.0215)$ and greater than the LT in females $13(p=0.008)$. The time to task failure (TTF) was greater at $90^{\circ}$ than $135^{\circ}$ for females and 14 males $(p=0.016 ; p=0.0193)$ respectively.

The PSET causes fatigue in all of the muscles that were tested, with the PD

16 fatiguing at a greater rate compared to one muscle for each sex. This investigation

17 supports using TTF as a clinical measure of shoulder girdle endurance at $90^{\circ}$ shoulder 18 abduction. 


\section{Introduction}

Muscular fatigue in the shoulder girdle has been cited as contributing to pain with overhead, repetitive movements (Chopp-Hurley et al., 2015, Chopp et al., 2010). Muscular endurance is the ability of a muscle to sustain activity performed as an isometric or isotonic contraction. Local ischemia created by a fatigued muscle or compressed tendon can cause structural weakness, whereby limiting local control, and in the rotator cuff tendon, may lead to an inability to control the humeral head during shoulder elevation (Firat and Turker, 2012). This notion supports the assumption that tension overload creates changes to the stability and control of the shoulder girdle. Examining elite swimmers identified training volume as a contributor to muscular pain more than the presence of instability (Sein et al., 2010). Supporting that muscular endurance is a contributing factor in preventing shoulder pain. However, muscular fatigue in the shoulder girdle has received limited research attention (Day et al., 2015, Ebaugh et al., 2006, Moore et al., 2013), and is not commonly evaluated clinically, as no standard test exists.

The Posterior Shoulder Endurance Test (PSET) was initially described by Moore et al. (Moore et al., 2013) as an isotonic test performed in a prone position while lifting the arm to $90^{\circ}$ of horizontal abduction at a shoulder abduction angle of $90^{\circ}$ at 30 beats per minute. An isometric version of the PSET at $135^{\circ}$ of shoulder abduction was modified for patients with lateral epicondylagia (Day et al., 2015). Patients with lateral epicondylagia had significantly less endurance than a comparison group without symptoms (Day et al., 2015). However, given that individuals with non-traumatic shoulder pain often have limited range of motion (Chopp-Hurley and Dickerson, 2015), 
45 the $135^{\circ}$ shoulder abduction position may not be optimal. While the PSET shows

46 promise as a clinical measure for posterior shoulder endurance, the two variations need

47 further evaluation to determine which muscles are being fatigued, and to identify any

48 differences between the two positions.

Reductions in electrical conduction and availability of ATP are common causes of local muscular fatigue (Brooks GA, 2005). Because surface EMG can detect the

51 electrical activity of the muscle, using the power spectrum, the median frequency (MF)

52 of the muscle is representative of muscular fatigue (Vollestad, 1997). Surface EMG has

53 been used in multiple studies examining the fatigue characteristics of the shoulder using 54 the power spectrum (Vollestad, 1997, Szucs et al., 2009, Tse et al., 2015, Minning et 55 al., 2007).

The primary purpose of this study was to determine if the posterior shoulder

57 muscles were selectively fatigued during the initial phase of the PSET in the $90^{\circ}$ and

$58135^{\circ}$ positions. A secondary purpose was to determine if there was a difference in the 59 time to task failure (TTF) of the PSET between the $90^{\circ}$ and $135^{\circ}$ positions.

\section{Methods}

There were 31 females $(\mathrm{Age}=19.9 \pm 1.5$ years; weight $=65.8 \pm 7.9 \mathrm{Kg}$;

62 height $=166.0 \pm 7.0 \mathrm{~cm}$ ) and 24 males (Age $=25.5 \pm 4.2$ years; weight $=84.3 \pm 11.0 \mathrm{Kg}$;

63 height $=175.7 \pm 7.4 \mathrm{~cm}$ ) in this study. Potential participants were included if they had 64 normal pain-free shoulder mobility. Exclusion criteria included individuals with shoulder 65 pain, individuals that had a history of shoulder surgery, and individuals that had 
neurological disorders that would exclude them from performing the PSET. All participants were provided and signed an university approved informed consent

Participants completed an ordinal scale question which asked them to answer "How many hours per week do you use weights for your upper body?". Participants could choose "1 hour", "2-3 hours", "4-5 hours", "6-7 hours", "8-9 hours" or "10+ hours". Participants also completed the Shoulder Activity Scale questionnaire (Brophy et al., 2005) to determine level activity for their upper extremity.

The dominant arm was used in all cases during testing. Lean tissue mass of the upper extremity was estimated using the Hayne's equation. Hayne's equation required measuring the girth of the arm (at the midpoint between the angle of the acromion and the tip of the olecranon process) and the triceps skin fold measurement is used (McArdle WD, 2015). Skin was prepared for electrode placement by shaving any hair, using sandpaper, and isopropyl alcohol (Soderberg, 1992). The length of the upper extremity was measured from the acromioclavicular joint to the distal end of the radial styloid process with the elbow straight. Body weight, and height were obtained. Using the measured bodyweight and arm length the external torque needed to reach the standardized level was determined. The external torque was standardized based on published anthropometric data using the $50^{\text {th }}$ percentile for both males and females (Chaffin DB, 1999). Based on pilot testing, males used an external torque of $21 \pm 1 \mathrm{Nm}$ and females used an external torque of $13 \pm 1 \mathrm{Nm}$. Once the anthropometric data estimated the torque provided by the arm alone, an additional external load was provided to the nearest $0.23 \mathrm{~kg}$. The external load in males ranged from $2.05-2.5 \mathrm{Kg}$, and the external load ranged in females from 1.36-1.59 Kg. Prior to testing, participants 
performed a 5-minute warm-up on a Biodex Upper Body Ergometer, and were familiarized with testing procedures.

Electromyographic data were collected using Noraxon MyoMuscle v.MR3.8.6 (Noraxon USA, Inc., Scottsdale, AZ, USA) with the following characteristics: CMRR was greater than $100 \mathrm{~dB}$ at $50 \mathrm{~Hz}$; electromyographic signals were recorded at a sampling rate of $1500 \mathrm{~Hz}$. Noraxon dual self-adhesive $\mathrm{Ag} / \mathrm{AgCl}$ snap electrodes with a

$2.0 \mathrm{~cm}$ inter-electrode distance were attached to Noraxon DTS sensors, which communicated with Noraxon MyoMuscle transmitter.

Self-adhesive electrodes were placed parallel to the muscle fiber direction on the posterior deltoid (PD), upper trapezius (UT), middle trapezius (MT), lower trapezius (LT), and infraspinatus (INF) according to SENIAM standards (Hermens et al., 2000) and published data (FIGURE 1) (Soderberg, 1992, Waite et al., 2010). The PD electrodes were placed $3 \mathrm{~cm}$ inferior to the angle of the acromial process. The UT electrodes were placed between the midpoint of $\mathrm{C} 7$ spinous process and the acromion process. The MT electrodes were placed between the midpoint of T3 spinous process and the medial border of the root of the scapula. The LT electrodes were placed 2/3 distance from the superior medial angle of the scapula to T8 spinous process. The INF electrodes were placed $4 \mathrm{~cm}$ inferior from the middle spine of the scapula.

The PSET was performed with participant in prone with arm at $90^{\circ}$ and $135^{\circ}$ shoulder abduction angles (FIGURE 2, 3) A stand-alone target was used to assured participants remained in the testing position throughout each trial. Participants were instructed to maintain contact with the target, but not to excessively push into the target. The researchers provided verbal encouragement. The trial was finished when the 
112 participant failed to maintain contact with the target, demonstrated excessive

113 substitution patterns, or voluntarily stopped. Researchers measured time to task failure

114 (TTF) with a stopwatch. Testing position was alternated between subjects, and

115 participants were given 15 minutes of recovery between the test positions (Lariviere et 116 al., 2003).

Noraxon MyoMuscle software was used to analyze the raw EMG signals. This analysis converts the EMG signal into the power spectrum using the Fast Fournier 119 Transformation $\left(|\mathrm{FFT}(\mathrm{x})|^{\wedge} 2\right)$ and then calculates the median frequency (MF) for each 120 second of activity creating a slope of median frequency. Median frequency for the first 12120 seconds (MF20) of the activity were used for analysis in order to compare the same 122 amount of time across participants $\left(90^{\circ}\right.$ Range $=31-91$ seconds; $135^{\circ}$ Range $=23-83$ 123 seconds). Male and female participants used differing external torque loads and were 124 analyzed separately. associations with MF20. Considered co-variants included were muscle (PD, UT, LT, 127 MT, and INF), position $\left(90^{\circ}\right.$ and $\left.135^{\circ}\right)$, BMI, triceps lean muscle mass, Shoulder activity scale questionnaire (Brophy et al., 2005), and the ordinal scale question for time of exercise. An a priori alpha level $=0.05$ was set for all statistical tests, and Tukey130 Kramer (Adj. p) was used for post-hoc pair-wise comparisons when appropriate. TTF of 131 the PSET was measured in seconds for the total duration of the test. Paired t-tests 132 compared the TTF separately for males and females. All analyses were performed 133 using SAS (v. 9.4).

\section{Results}


The final model for the female subjects found significant differences in the MF20 slope by the posterior shoulder muscles (PD, UT, MT, LT, and INF), position ( $90^{\circ}$ and $135^{\circ}$ ), and lean tissue mass of the humerus. The final model for males only found significant differences in the MF20 slope by the posterior shoulder muscles (PD, UT, MT, LT, and INF).

Female Results

The repeated measures regression model of the MF20 slopes showed that there was a significant difference between muscles while controlling for position and triceps lean muscle mass. Body Mass Index (BMI), shoulder activity scale questionnaire and ordinal scale question were not retained in the final model. Pairwise comparisons revealed the PD (mean \pm SE $=-0.81 \pm 0.04)$ was greater than the LT $(-0.58 \pm 0.04)$ (Adj. $p=0.0077)$ for MF20 but all other muscles fatigued at the same rate (FIGURE 4). The model identified a significant difference between in MF20 between the $135^{\circ}(-0.749 \pm$ $.03)$ and $90^{\circ}(-0.63 \pm .03$, Adj. $p=.0009)$ position (FIGURE 5). With every one unit of area increase in triceps lean muscle mass $\left(\mathrm{cm}^{2}\right)$ the slope of fatigue was decreased by $0.01(p=.0002)$. The paired t-test examining the TTF between positions revealed that $90^{\circ}$ position (58.1 \pm 2.4 seconds) required longer time than the $135^{\circ}$ position $(49.2 \pm 2.5$ seconds) $(p=.016)($ FIGURE 7).

Male Results

The repeated measures regression model of MF20 slopes showed that there was a significant difference in slopes between muscles $(p=.018)$. Position, BMI, shoulder activity scale, exercise scale, and triceps lean muscle mass were not retrained in the 
157 final model. Pairwise comparison between the MF20 slopes revealed that only PD ($0.87 \pm 0.08)$ slope was greater that the UT $(-0.59 \pm 0.09)$ slope (Adj. $p=0.02)$, and all other muscles fatigued at the same rate (FIGURE 6). MF20 was not significantly difference by position $(p=.223)$. The paired t-test examining TTF revealed that the $90^{\circ}$ position ( $68.5 \pm 2.8$ seconds) required a longer time to reach fatigue than the $135^{\circ}$ position (59.6 \pm 2.4 seconds) $(p=.019)$ (FIGURE 7).

\section{Discussion}

The results of the current investigation examined fatigue of 5 posterior shoulder muscles during the PSET at two different shoulder abduction angles suggest the PSET is a measure of multiple shoulder girdle muscles fatiguing at a similar rate. The MF20 slope was decreasing at nearly the same rate in all muscles tested for both men and women (FIGURE 4,6). Previous studies have demonstrated that many shoulder girdle muscles work synergistically to control the position of the scapula for optimal function

170 (Cools et al., 2007, Cools et al., 2002, Merolla et al., 2010). While certain positions may bias different scapular stabilizers (De Mey et al., 2013, Arlotta et al., 2011, Ha et al., 2012), coordination of the muscle contraction varies amongst individuals (Phadke and

173 Ludewig, 2013, Hawkes et al., 2012).

Posterior deltoid is most active during horizontal abduction suggesting it is a 175 prime mover (Pearl et al., 1992). The current study showed that when accounting for 176 other controlling factors, the PD muscle fatigued similarly to all the other muscles except 177 for the UT in males and LT in females. Using the positon of horizontal abduction, likely 178 accounts for the PD to fatigue at steeper slope than two of the muscles but not all. A 179 cross-sectional EMG study that examined the middle deltoid (MD), UT, LT, and serratus 
anterior during a fatiguing task of shoulder elevation found the MD fatigued sooner than the other muscles tested. Similar to the current investigation, all of the muscles significantly fatigued during the task (Minning et al., 2007). While the current investigation did not measure the MD or serratus anterior, the three trapezius muscles behavior to fatigue were similar in both studies. Since torque is produced by multiplying the force and moment arm, and mechanical advantage is the ratio of the external moment arm and internal moment arm, adding the external load to the distal segment would reduce the muscle's mechanical advantage. Therefore, it is reasonable that the deltoid muscle, whether the MD or PD, would fatigue at a faster rate than the other muscles. However, there was no statistical difference in the median frequency slopes between the PD and the other muscles tested with the exception of one other muscle in each sex. Therefore, one could argue that the PSET is actually measuring muscle fatigue in multiple posterior shoulder girdle muscles. While the PD may be the prime mover, the other synergist muscles are also fatiguing similarly in the current investigation and the Minning et al. (2007) study.

When comparing the MF slopes between participants, it is important to calculate MF across the same time window. MF20 of the PSET were used for analysis because one participant was only able to hold the $135^{\circ}$ position for 23 seconds. However, since the majority of MF slope change occurred during the initial portion of the exercise, the first 20 seconds should represent muscle fatigue (Cifrek et al., 2009).

The vast majority of kinematic studies attribute reductions in upward rotation of the scapula, and posterior tilting to subacromial impingement (Ludewig and Reynolds, 2009). As shoulder abduction angles increases, scapular upward rotation and posterior 
203 tilting also increase. Therefore, the authors hypothesize the $135^{\circ}$ position of shoulder 204 abduction may create subacromial space narrowing, preventing individuals with 205 shoulder pain from performing the test. Additionally, exercise prescription for muscular 206 endurance includes resistance training at relatively light external torque loads while 207 performing static holds or a high number of repetitions (Campos et al., 2002).

208 Therefore, using the test position that typically requires a longer duration may be 209 beneficial to measured muscular endurance as opposed to merely muscular strength.

210 Since the $90^{\circ}$ shoulder abduction position took approximately 10 second longer to 211 fatigue, it is reasonable to assume that the $90^{\circ}$ position would ensure muscular 212 endurance assessment better than the $135^{\circ}$ position in the absence of surface EMG 213 verification. Hence, the authors recommend using the $90^{\circ}$ shoulder abduction PSET 214 position since the $90^{\circ}$ position would likely be less painful in a population with shoulder 215 pathology, and this position would ensure assessment of muscular endurance rather 216 than muscular strength alone.

Since there were different external torques used between sexes, we were unable 218 to compare across male and female subjects. The decision to use different external 219 torques was based on pilot data a priori. Since the amount of external torque added to 220 the arm was determined from the participant's body weight and arm length, if similar 221 torques were used across sexes, the female participants would have had to hold larger 222 external loads than the male participants did. Therefore, females used an external 223 torque of $13 \pm 1 \mathrm{Nm}$, while males used an external torque of $21 \pm 1 \mathrm{Nm}$. This study has limitations to acknowledge. While proper SEMIAM guidelines 225 were followed for surface EMG electrode placement and data collection (Soderberg, 
1992), and the primary author consistently performed the electrode placement, surface EMG is still susceptible to cross talk from neighboring muscles. The possibility of using surface electrodes to estimate intramuscular muscle activity and using their mathematical formulas found that cross talk ranged from $4.4 \%$ to $17.3 \%$, with the cross talk being greatest in muscles that overlap one another (Waite et al., 2010). Based on their findings it is likely the supraspinatus was contributing to the surface EMG placement of the upper trapezius, and posterior deltoid.

Additionally, a limitation of spectral frequency analysis is that the muscle volume conductor may serve as a low-pass filter. This would also include differences in body fat and skin impedance differences between subjects. Thus, a high-velocity motor unit that is recruited deep in the tissue may be represented in the lower frequency portion of the power spectrum (Farina et al., 2002). This limitation may be another explanation of the PD fatiguing at a faster rate than the other muscles. While this limitation cannot be denied, median frequency has been used to objectively observe muscle fatigue elsewhere (Vollestad, 1997, Tse et al., 2015, Minning et al., 2007).

While clear definitions for muscle fatigue were used in this study, we could not control for what was leading to fatigue. Both peripheral and central factors may contribute to fatigue (Enoka and Duchateau, 2008). In fact, it appears that the cause of muscle fatigue may be task-specific. The current study did not measure peak torque, so presumably, the percentage of peak torque varied between participants. This difference in percentage of peak torque may contribute to how one fatigues. In order to improve the clinical utility of the PSET, the authors decided to use a standard external torque rather than a percentage of peak torque, so the test could be performed based 
249 on readily available information in a clinical setting. Additionally, the participant's

250 volitional effort is important for testing and control is limited in human studies.

Lastly, given the participants were young and free from shoulder pathology,

252 these results are not generalizable. Other studies have demonstrated that the amount

253 of muscle torque vary depending on training regimen (Garrandes et al., 2007),

254 neuromuscular activation patterns vary among sex (Clark et al., 2005), and peak torque

255 during a fatiguing task change depending on age (Baudry et al., 2007). Therefore, more

256 research is needed to make claims regarding these co-variants.

\section{Conclusion}

The findings conclude that the PSET causes fatigue in all of the muscles tested.

259 The PD fatigued significantly faster than the LT and UT in women and men respectively.

260 This study suggests that the PSET is testing the endurance of multiple posterior

261 shoulder girdle muscles, not a specific muscle. Further studies need to consider other

262 muscles that may impart some amount of stabilization to the shoulder complex. Time to

263 task failure may prove a useful clinical measure of shoulder girdle endurance at $90^{\circ}$ of

264 shoulder abduction. Future studies should investigate if the PSET is can discriminate

265 between individuals with and without shoulder pain, and if the PSET is a clinically

266 reliable test.

\section{Acknowledgements}

268 The authors would like to thank all participants in this study, the student research

269 assistants for their role in data collection, the

for providing space and supplies to perform this research. 
ARLOTTA, M., LOVASCO, G. \& MCLEAN, L. 2011. Selective recruitment of the lower fibers of the trapezius muscle. J Electromyogr Kinesiol, 21, 403-10.

BAUDRY, S., KLASS, M., PASQUET, B. \& DUCHATEAU, J. 2007. Age-related fatigability of the ankle dorsiflexor muscles during concentric and eccentric contractions. Eur J Appl Physiol, 100, 515-25.

BROOKS GA, F. T., BALDWIN KM 2005. Exercise Physiology: Human Bioenergetics and its Applications, New York, NY, McGraw Hill

BROPHY, R. H., BEAUVAIS, R. L., JONES, E. C., CORDASCO, F. A. \& MARX, R. G. 2005. Measurement of shoulder activity level. Clin Orthop Relat Res, 439, 101-8.

CAMPOS, G. E., LUECKE, T. J., WENDELN, H. K., TOMA, K., HAGERMAN, F. C., MURRAY, T. F., RAGG, K. E., RATAMESS, N. A., KRAEMER, W. J. \& STARON, R. S. 2002. Muscular adaptations in response to three different resistance-training regimens: specificity of repetition maximum training zones. Eur J Appl Physiol, 88, 50-60.

CHAFFIN DB, A. G., MARTIN BJ 1999. Occupational Biomechanics, New York, NY, John Wiley \& Sons, Inc. . CHOPP-HURLEY, J. N. \& DICKERSON, C. R. 2015. The potential role of upper extremity muscle fatigue in the generation of extrinsic subacromial impingement syndrome: a kinematic perspective. Physical Therapy Reviews, 20, 201-209.

CHOPP-HURLEY, J. N., O'NEILL, J. M., MCDONALD, A. C., MACIUKIEWICZ, J. M. \& DICKERSON, C. R. 2015. Fatigue-induced glenohumeral and scapulothoracic kinematic variability: Implications for subacromial space reduction. J Electromyogr Kinesiol.

CHOPP, J. N., O'NEILL, J. M., HURLEY, K. \& DICKERSON, C. R. 2010. Superior humeral head migration occurs after a protocol designed to fatigue the rotator cuff: a radiographic analysis. J Shoulder Elbow Surg, 19, 1137-44.

CIFREK, M., MEDVED, V., TONKOVIC, S. \& OSTOJIC, S. 2009. Surface EMG based muscle fatigue evaluation in biomechanics. Clin Biomech (Bristol, Avon), 24, 327-40.

CLARK, B. C., COLLIER, S. R., MANINI, T. M. \& PLOUTZ-SNYDER, L. L. 2005. Sex differences in muscle fatigability and activation patterns of the human quadriceps femoris. Eur J Appl Physiol, 94, 196206.

COOLS, A. M., DEWITTE, V., LANSZWEERT, F., NOTEBAERT, D., ROETS, A., SOETENS, B., CAGNIE, B. \& WITVROUW, E. E. 2007. Rehabilitation of scapular muscle balance: which exercises to prescribe? Am J Sports Med, 35, 1744-51.

COOLS, A. M., WITVROUW, E. E., DE CLERCQ, G. A., DANNEELS, L. A., WILLEMS, T. M., CAMBIER, D. C. \& VOIGHT, M. L. 2002. Scapular muscle recruitment pattern: electromyographic response of the trapezius muscle to sudden shoulder movement before and after a fatiguing exercise. $J$ Orthop Sports Phys Ther, 32, 221-9.

DAY, J. M., BUSH, H., NITZ, A. J. \& UHL, T. L. 2015. Scapular muscle performance in individuals with lateral epicondylalgia. J Orthop Sports Phys Ther, 45, 414-24.

DE MEY, K., DANNEELS, L., CAGNIE, B., VAN DEN BOSCH, L., FLIER, J. \& COOLS, A. M. 2013. Kinetic chain influences on upper and lower trapezius muscle activation during eight variations of a scapular retraction exercise in overhead athletes. J Sci Med Sport, 16, 65-70.

EBAUGH, D. D., MCCLURE, P. W. \& KARDUNA, A. R. 2006. Effects of shoulder muscle fatigue caused by repetitive overhead activities on scapulothoracic and glenohumeral kinematics. J Electromyogr Kinesiol, 16, 224-35.

ENOKA, R. M. \& DUCHATEAU, J. 2008. Muscle fatigue: what, why and how it influences muscle function. J Physiol, 586, 11-23. 
FARINA, D., MADELEINE, P., GRAVEN-NIELSEN, T., MERLETTI, R. \& ARENDT-NIELSEN, L. 2002. Standardising surface electromyogram recordings for assessment of activity and fatigue in the human upper trapezius muscle. European Journal Of Applied Physiology, 86, 469-478.

FIRAT, T. \& TURKER, T. 2012. Is the long sarcomere length responsible for non-traumatic supraspinatus tendinopathy? Potential novel pathophysiology and implications for physiotherapy. Pathophysiology, 19, 179-83.

GARRANDES, F., COLSON, S. S., PENSINI, M., SEYNNES, O. \& LEGROS, P. 2007. Neuromuscular fatigue profile in endurance-trained and power-trained athletes. Med Sci Sports Exerc, 39, 149-58.

HA, S. M., KWON, O. Y., CYNN, H. S., LEE, W. H., PARK, K. N., KIM, S. H. \& JUNG, D. Y. 2012. Comparison of electromyographic activity of the lower trapezius and serratus anterior muscle in different arm-lifting scapular posterior tilt exercises. Phys Ther Sport, 13, 227-32.

HAWKES, D. H., ALIZADEHKHAIYAT, O., KEMP, G. J., FISHER, A. C., ROEBUCK, M. M. \& FROSTICK, S. P. 2012. Shoulder muscle activation and coordination in patients with a massive rotator cuff tear: an electromyographic study. J Orthop Res, 30, 1140-6.

HERMENS, H. J., FRERIKS, B., DISSELHORST-KLUG, C. \& RAU, G. 2000. Development of recommendations for SEMG sensors and sensor placement procedures. J Electromyogr Kinesiol, 10, 361-74.

LARIVIERE, C., GRAVEL, D., ARSENAULT, A. B., GAGNON, D. \& LOISEL, P. 2003. Muscle recovery from a short fatigue test and consequence on the reliability of EMG indices of fatigue. Eur J Appl Physiol, 89, 171-6.

LUDEWIG, P. M. \& REYNOLDS, J. F. 2009. The association of scapular kinematics and glenohumeral joint pathologies. J Orthop Sports Phys Ther, 39, 90-104.

MCARDLE WD, K. F., KATCH VL 2015. Exercise Physiology: Nutrition, Energy, and Human Performance, Baltimore, MD, Wolters Kluwer Health/Lippincott Williams \& Wilkins.

MEROLLA, G., DE SANTIS, E., CAMPI, F., PALADINI, P. \& PORCELLINI, G. 2010. Supraspinatus and infraspinatus weakness in overhead athletes with scapular dyskinesis: strength assessment before and after restoration of scapular musculature balance. Musculoskelet Surg, 94, 119-25.

MINNING, S., ELIOT, C. A., UHL, T. L. \& MALONE, T. R. 2007. EMG analysis of shoulder muscle fatigue during resisted isometric shoulder elevation. J Electromyogr Kinesiol, 17, 153-9.

MOORE, S. D., UHL, T. L. \& KIBLER, W. B. 2013. Improvements in shoulder endurance following a baseball-specific strengthening program in high school baseball players. Sports Health, 5, 233-8.

PEARL, M. L., PERRY, J., TORBURN, L. \& GORDON, L. H. 1992. An electromyographic analysis of the shoulder during cones and planes of arm motion. Clin Orthop Relat Res, 116-27.

PHADKE, V. \& LUDEWIG, P. M. 2013. Study of the scapular muscle latency and deactivation time in people with and without shoulder impingement. J Electromyogr Kinesiol, 23, 469-75.

SEIN, M. L., WALTON, J., LINKLATER, J., APPLEYARD, R., KIRKBRIDE, B., KUAH, D. \& MURRELL, G. A. 2010. Shoulder pain in elite swimmers: primarily due to swim-volume-induced supraspinatus tendinopathy. Br J Sports Med, 44, 105-13.

SODERBERG, G. L. 1992. Selected topics in surface elctromyography for use in the occupational setting: expert perspectives. In: SERVICES, U. D. H. H. (ed.). Washington D.C.: National Institute Occupational Safety Health.

SZUCS, K., NAVALGUND, A. \& BORSTAD, J. D. 2009. Scapular muscle activation and co-activation following a fatigue task. Medical \& Biological Engineering \& Computing, 47, 487-495.

TSE, C. T., MCDONALD, A. C. \& KEIR, P. J. 2015. Adaptations to isolated shoulder fatigue during simulated repetitive work. Part I: Fatigue. J Electromyogr Kinesiol.

VOLLESTAD, N. K. 1997. Measurement of human muscle fatigue. J Neurosci Methods, 74, 219-27.

WAITE, D. L., BROOKHAM, R. L. \& DICKERSON, C. R. 2010. On the suitability of using surface electrode placements to estimate muscle activity of the rotator cuff as recorded by intramuscular electrodes. Journal of Electromyography \& Kinesiology, 20, 903-911. 
FIGURE 1. Electrode Placement of the 5 posterior shoulder muscles tested

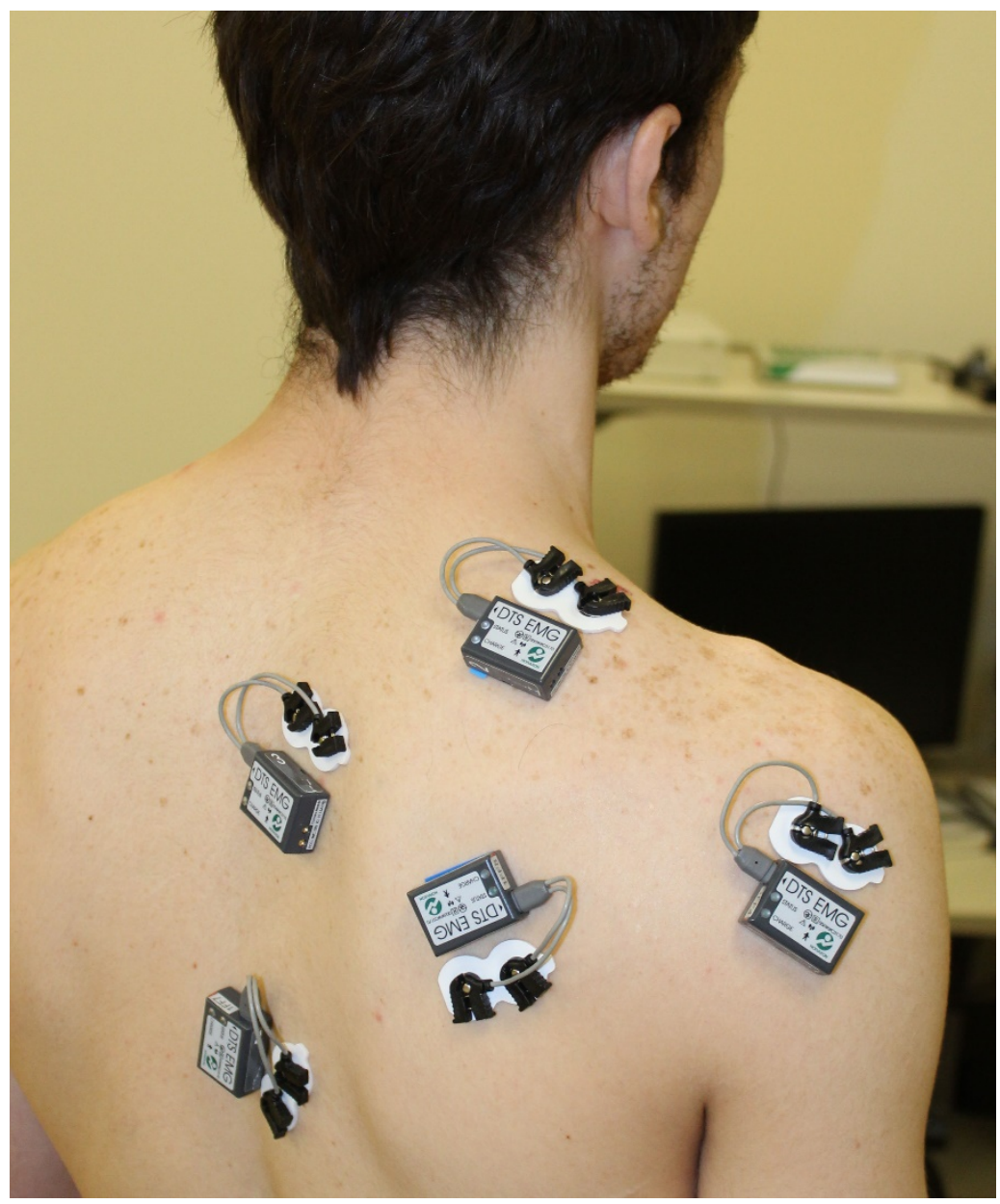


FIGURE 2. Posterior Shoulder Endurance Test Position at $90^{\circ}$ horizontal abduction

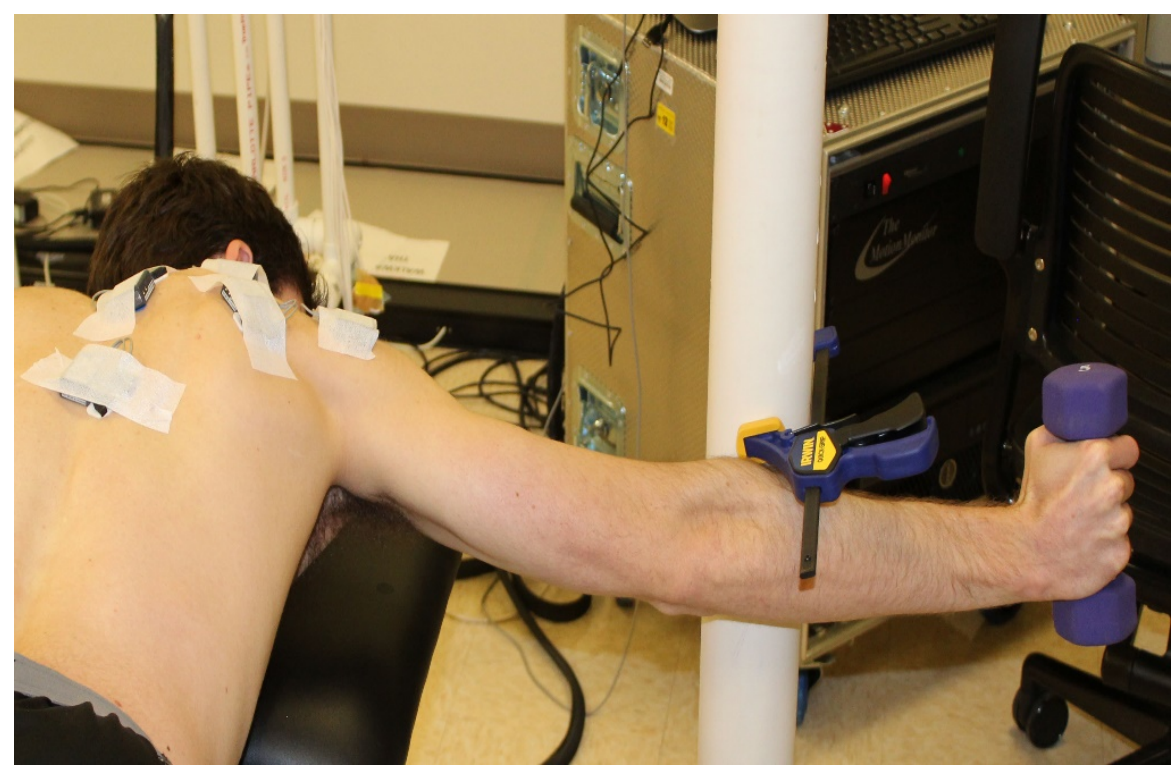


Figure 3. Posterior Shoulder Endurance Test Position at $135^{\circ}$ horizontal abduction

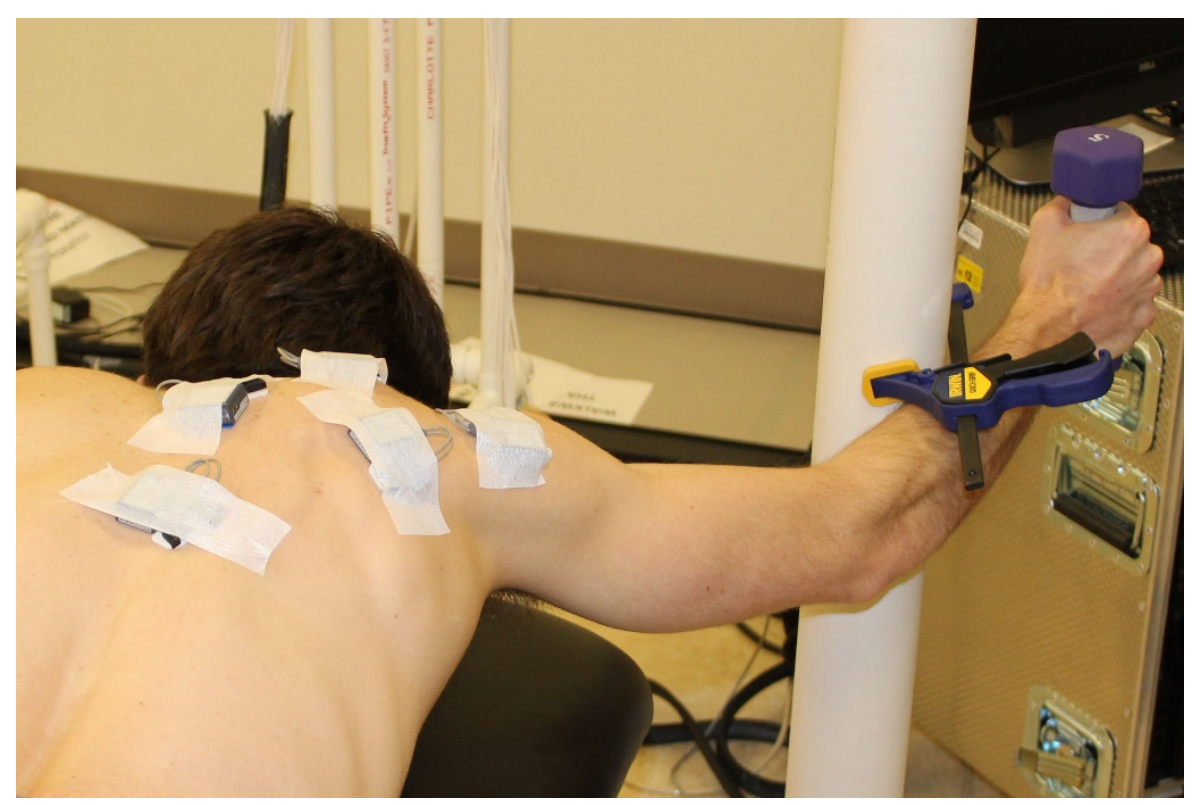


Figure 4. Female MF20 slope by muscles. The final model included position $\left(90^{\circ}\right.$ and $135^{\circ}$ ) and lean tissue mass of the humerus. $\mathrm{N}=62$ because each muscle was tested over both $90^{\circ}$ and $135^{\circ}$.

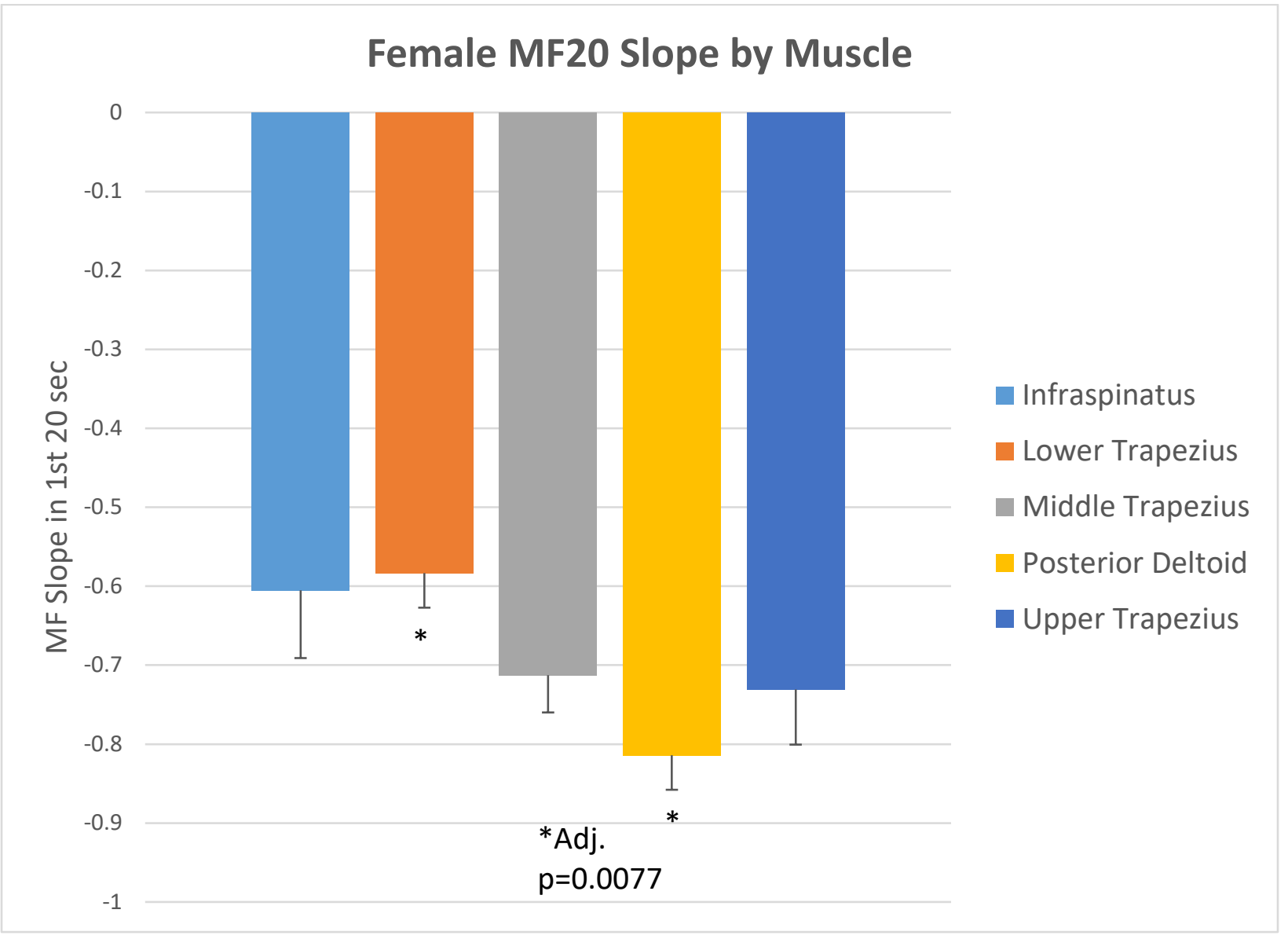


Figure 5. Female MF20 slope by position.

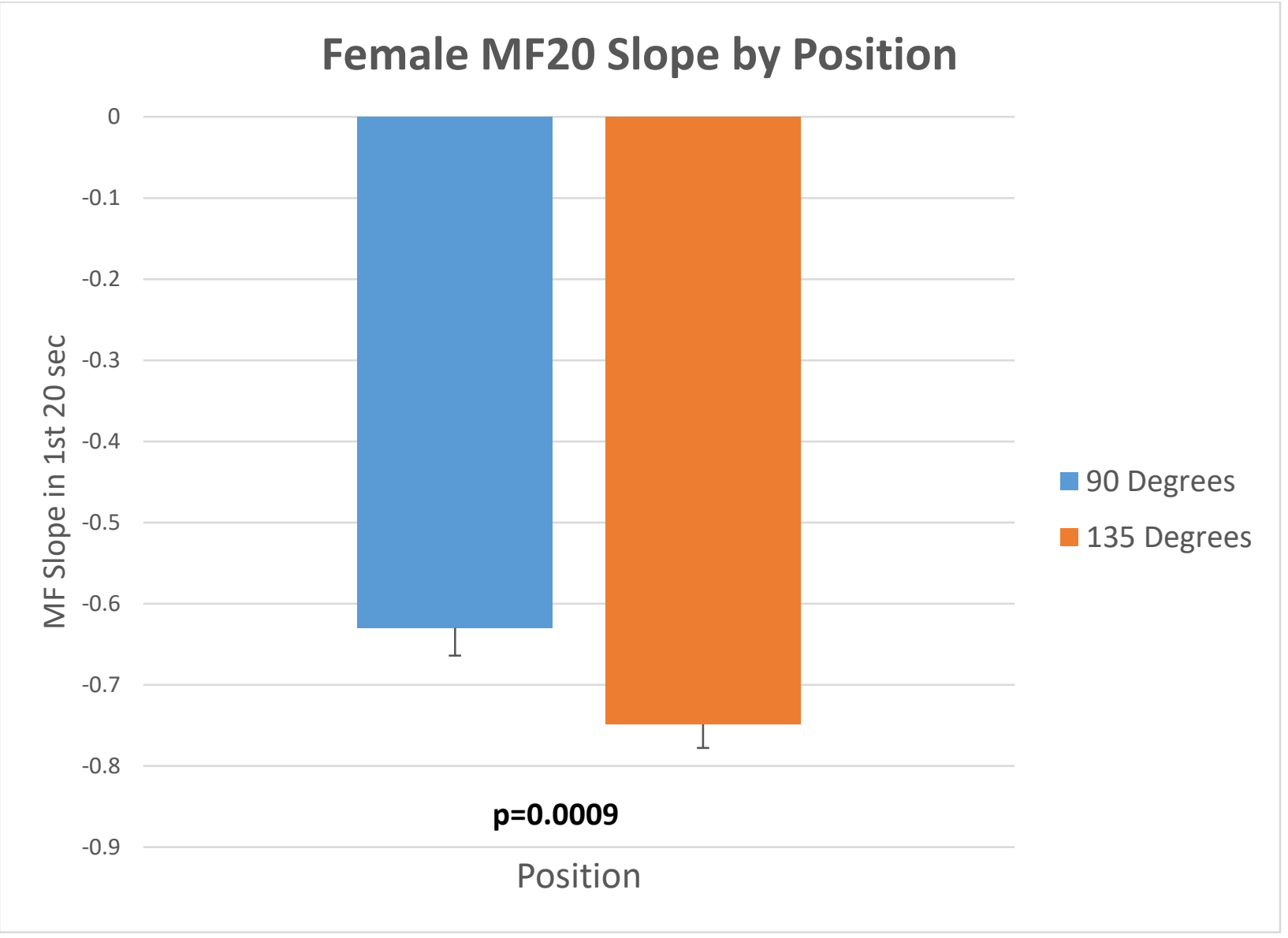


Figure 6. Male MF20 slope by muscles. The final model included muscle only. $\mathrm{N}=48$ because each muscle was tested over both $90^{\circ}$ and $135^{\circ}$.

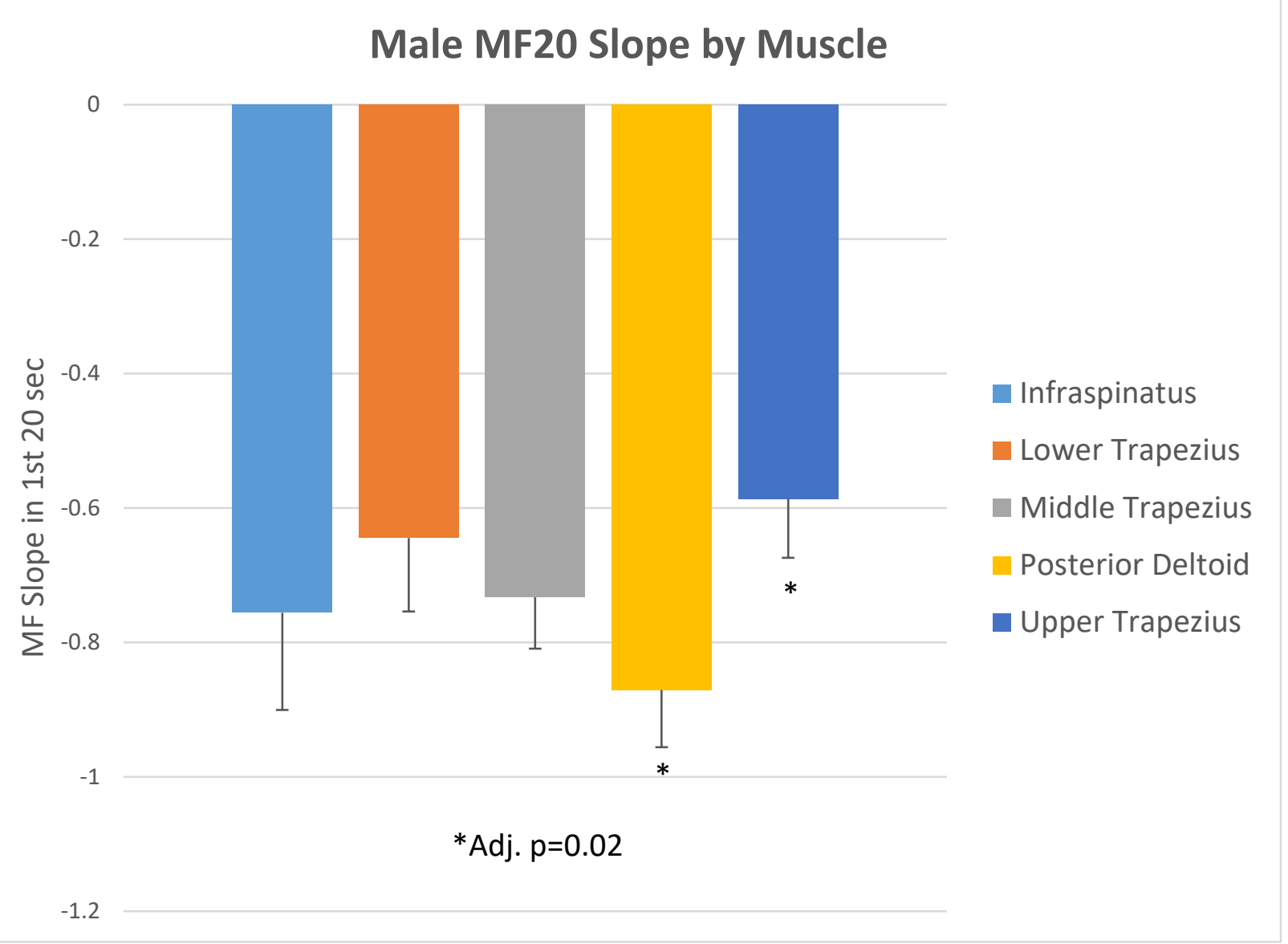


Figure 7. A comparison of the $90^{\circ}$ and $135^{\circ}$ position and TTF for females and males. Each sex was compared separately.

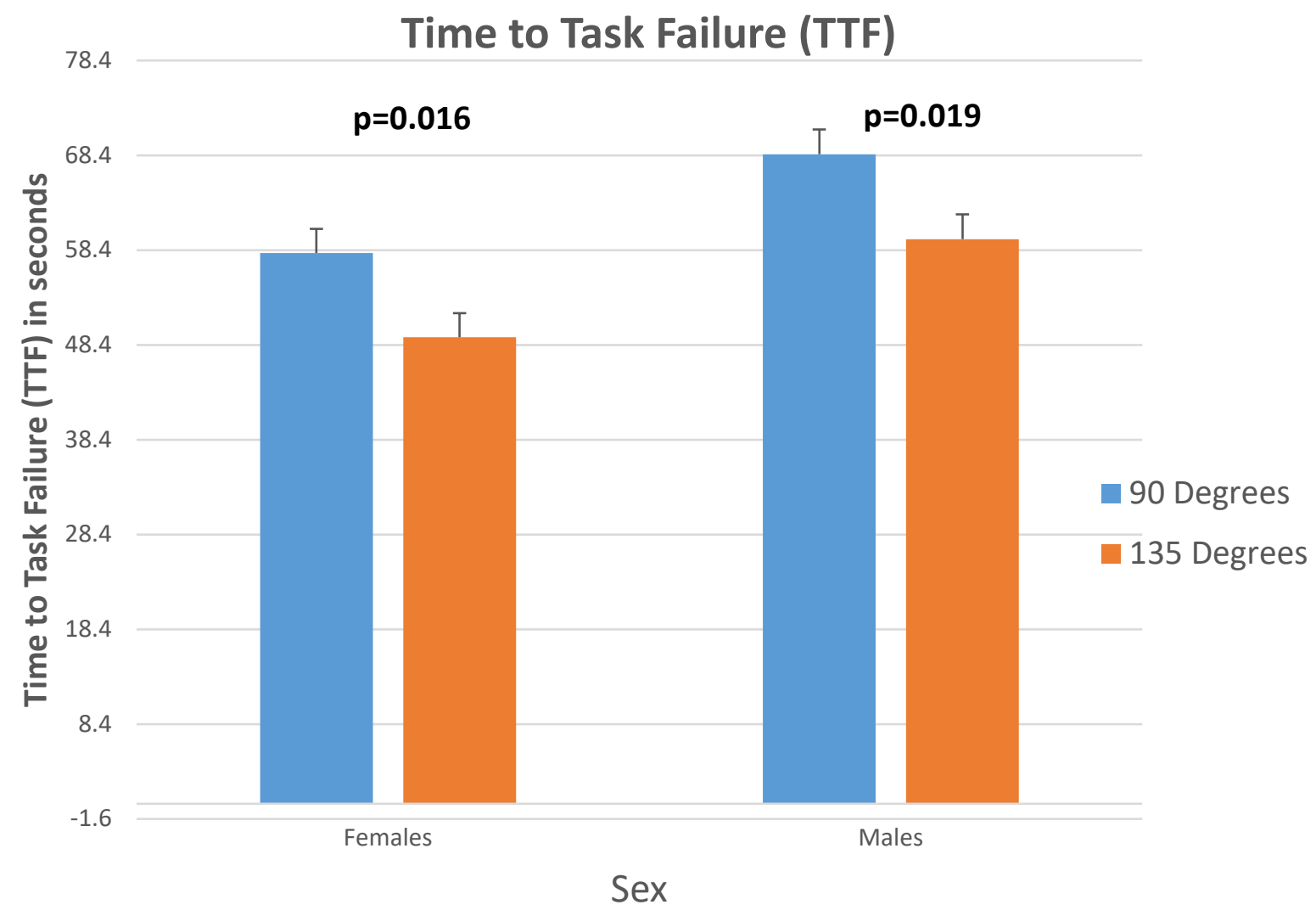

